\title{
MENTAL PATHOLOGY.'
}

BY PROFESSOR PIERRE JANET,

Collège de France.

GentLemen: I feel that it is a great honor to be called upon to address the Section of Pathological Psychology in the St. Louis Congress. The United States has done much for psychology. Your magnificent laboratories, your important publications, and your eminent men who have devoted themselves in great numbers to psychological investigation, have contributed abundantly to the development of the science. We are pleased to come and admire your work; we are proud to bring to you the results of our own investigations.

I am the more encouraged to present to you the greetings of the psychologists of France, by the fact that we have been concerned chiefly with the somewhat specialized topic of pathological or abnormal psychology to which this section of the Congress is to be devoted. If I mistake not, the investigators of other countries tend to separate two branches of study which we are disposed to unite; they study on the one hand, the psychology of the normal individual, or the individual who is regarded as being normal, and on the other hand, they are concerned with mental diseases, their analysis and especially their classification. It seems to me that we in France, under the influence of two of my masters, Ribot and Charcot, whose names I am pleased to recall to you, have endeavored rather to throw light upon psychiatry by a study of normal psychology; and to regard mental diseases as experiments which have been cunningly devised by nature to show us such suppressions and modifications of function as the experimental method demands. Our psychological laboratories, situated as they often are in hospitals for nervous and mental diseases, as at the Salpétrèire, at Ste. Anne and at

${ }^{2}$ Address delivered at the Congress of Arts and Science, St. Louis. Translated by J. W. Baird, Johns Hopkins University. 
Villejuif, have endeavored to unite the psychologist and the alienist in a common investigation.

This union, alike in France and in other countries where it has also been accomplished, seems to me to have been advantageous to both sciences. In psychiatry it has to some extent turned the investigator aside from investigations which are actually useless because they cannot be utilized. One is scarcely able, even to-day, to make a complete classification of mental disorders from a single point of view as is required by logic. As $Z$ iehen has remarked, mental diseases are classified differently from the standpoint of symptoms, of etiology, of evolution and of pathological anatomy. Moreover, it must be confessed that we do not know the real causes of mental diseases; and it is bootless to disguise our ignorance by a cloak of philosophical speculation or of hypothetical anatomy. The pathological psychologist has recognized that he must begin at the beginning. He has endeavored to penetrate more thoroughly and more sympathetically into the mental states of the diseased; he has attained greater accuracy in the analysis of symptoms; he has observed and, so far as possible, has measured the alterations of psychical function. In short, psychological experimentation has introduced into psychiatry a rehabilitation and a refinement of the clinical method.

The older psychology, permeated as it was throughout with philosophical speculation, claimed to find that the mental states were as simple and as unchanging as its theories. It studied memory in general, reason in general, the theoretical and abstract will, without first taking up the question as to what constitutes memory, reason and will in a particular individual, under particular conditions, at a particular age, in a particular state of health. The investigation of pathological conditions has forced it to recognize that these phenomena are not fixed and immutable; it has come to see that they wax and wane, that they are subject to change, and that a multitude of degrees are represented in their developmental transformations. Psychology has thus been led to seek, even in the normal individual, for those changes and oscillations which it has found to be characteristic of the abnormal individual; it is no longer abstract, but has 
become a more real and living thing. If one may use the expression, it has ceased to be purely static, and has become dynamic. The study of the oscillations of mind which have been brought to light by pathological psychology, has called attention to a group of phenomena which can scarcely be classified among the older faculties, and have been neglected as being of no significance - the phenomena of fatigue, of sleep, of the emotions, of the various forms of intoxication, of the neuropathic disorders. It has also called attention to the opposite modifications which occur in repose, in the waking state, in calmness and sang froid, and in convalescence (even though it be but temporary). These modifications constitute the most apparent oscillations of mind. Permit me to lay emphasis upon these depressions and these excitations, and to remind you of the investigations which have been made in this connection. The topics which have not yet been investigated are of even greater significance; they represent the most important of the present problems of pathological psychology.

One of the first modifications of mental states to which I wish to call attention, is illustrated by the semi-normal, semi-pathological condition which is induced by fatigue. It is a familiar fact that the physical and mental being does not always maintain a constant condition; that it is incapable of manifesting uniform phenomena when submitted to prolonged effort; that its functions vary from the beginning to the end of a period of work. And the change induced is essentially of the same character whether the work be physical or mental. The investigation of fatigue dates from an early period. You doubtless recall an old observation by Holland which has been cited by Ribot." "An engineer relates the following experience: "When I was down in a mine, I felt myself overcome with fatigue and lassitude to such a degree that I found it impossible to converse with the German inspector who accompanied me. Every word, every phrase of the German language had escaped my memory, and I recovered them only after taking nourishment and rest." "Here we have a first well-marked opposition between the normal state and the state of fatigue. Oppositions of this sort have been the

'Ribot, Maladies de la mémoire, p. II4. 
object of numerous investigations, among which may be mentioned Galton's interesting study of the influence of fatigue and overwork in schools, the investigations of a great many German authors, instigated for the most part by Kraepelin, the remarkable observations of the French physician Tissie, who made a physiological and psychological examination of the contestants in various forms of athletic sports, the investigations of Féré, of Binet and Henri, etc. All of these investigations show the presence of modifications of constant character.

It is to be noted first of all, that an apparent exaggeration of function occurs with the advent of fatigue. This functional change makes its appearance in the form of a physical agitation, or in other words, an exaggeration of movement. Galton found signs of fatigue when he examined the posture of a subject to whom a difficult passage was being read aloud. The fatigued auditor yawns, stretches himself, shifts his position and contracts certain facial muscles. In school-children one may observe movements of the eye-brows, of the lips, of the forehead, and of the fingers; and if the degree of fatigue be increased, these movements soon pass over into chorea and tic. Experimental investigations, such as those of Sommer and Bettmann, have revealed the presence of a modification of the reflexes and an increase in the number of tremors in the ergographic curve. Pathological investigations have shown an exaggeration of the reflexes, an extension of innervation to the unused muscles, an involuntary laugh, a muscular tremor, and spasms of various sorts, etc. The agitation induced by fatigue may also be visceral; I cannot lay too much stress upon the spasms of the digestive organs, the changes of respiratory rhythm, the profuse perspirations. The agitation may even be mental. Galton observed irritability, ill-humor, a tendency to magnify small things; and more recently, attention has been called to various forms of fancies which take possession of the mind and may even degenerate into pathological obsessions. The subject is well aware that something abnormal is taking place within him; he is conscious of certain abnormal sensations. Galton emphasized the feeling of incapacity which increases with increase of fatigue; Oehrn, in 1895 , and more particularly Tissié laid stress upon 
the feeling of weariness as a characteristic symptom of fatigue. These phenomena are observed alike in bicyclists, in children who do mental work and in subjects who repeatedly perform an experiment. These feelings correspond to something which is perfectly real; it is possible to demonstrate in various ways that a decrease of mental function runs parallel with the agitation. Whether we examine the subject's penmanship, or measure his capacity to insert a needle into holes in a perforated plate - as I did in 1889 , and as Bryan has done since - we invariably find a lack of dexterity, a lesser precision of movement. The diminished rapidity which is found to be characteristic of reactions and of all sorts of motor adjustments has been demonstrated in innumerable ways (Kraepelin, Oehrn, Burgerstein, Vaschide, Binet and Henri). On the other hand, attention and power of apprehension also decrease in considerable degree; and one finds an increase in the number of errors in tasks whose accomplishment depends upon automatic mental processes, or the mechanical association of ideas (Cattell, Finzi, Sikorsky, Hopfner, Burgerstein, Laser, Thorndike, Binet). The memory undergoes a change, as we saw from the illustration cited by Ribot; acquisition becomes more difficult (Ebbinghaus, Finzi, Schneider); the power of recollection, the certainty and the correctness of response decrease (Ranschburg), and certain classes of memories disappear entirely.

The disturbance even extends to perception (Grote, Marine, Griesbach, Leuba). All of these phenomena are in striking contrast with those that occur in repose. This opposition between the mind in the state of rest and in the state of fatigue, is of prime importance for pathological psychology.

Similar phenomena are to be observed in the various forms of intoxication; here too is to be seen an interesting opposition between the mental state of the intoxicated and of the nonintoxicated individual. Numerous investigations, such as those upon haschish by Tours, those upon alcohol by Richet, and many others, have established phenomena which are analogous to the phenomena of fatigue. But I wish to direct your attention to a class of investigations which has reached a high degree of development in France - those of sleep, or rather of sleeps, 
for there are many states to which this general name may be applied.

Sleep is a type of oscillation which is particularly deserving of notice in this connection, because it is a wholly relative condition; its phenomena can be determined only in relation to the waking state. An essential characteristic of sleep is the fact that it is attended by a lesser activity of the vital functions. It is not enough to say that sleep is a state in which the temperature of the body averages $36^{\circ}$, the pulmonary expiration is two liters, and the pulse is 54 . One must add that these phenomena occur in an organism which is capable when in another condition, of having a temperature of $37^{\circ}$, a respiration of nine liters, and a pulse of 7o. It may be said that the organism is unable to keep up its more active form of existence continuously, and that it practices economy during a part of its life. Nor is the oscillation solely physiological; it is mental as well. Dreams are the thoughts of the sleeping man. I need not remind you of all the investigations of dreams which have been made from the time of Hervey de Saint Denis and of Charma, down to the recent publication of Sante de Sanctis. Let me mention however that dreams are attended by a mental agitation which manifests itself in hallucinations, and in a ready association of images which arrange themselves into tableaux with interminable kaleidoscopic changes. Sense-impressions of slight intensity give rise to complex dreams of similar modality (Maury, Sergueyeff, Mourly-Vold). These dreams are characterized by exaggeration and repetition; the Cartesian flea-bite becomes a sword-thrust, and a trifling weight seems an Etna upon the chest. The same dream recurs countless times with wearying monotony. The memory of experiences long since past is vivified; the instincts and the habitual tendencies have free play and develop immoderately; even the hereditary tendencies may intervene in intense degree. It is true that the dreamer may feel that it is all unreal and fictitious, but he is carried along by the turbulence of his imagery, and he frequently experiences the most violent emotions from his images. Side by side with this exaggeration of certain mental functions there occurs a diminution of other mental functions; and some of the latter are most peculiar and extremely characteristic. 
It is evident that the consciousness of personality is disordered, and that a duality of personality tends to rise. Charma and Delboeuf report dreams in which a school-master asks them a question; they are unable to answer but a school-mate rises at their side and to their astonishment gives the correct answer. In another case the dreamer says to a child: "Be careful that you do not tumble," and he himself slips. Thereupon the child replies : "Why don't you follow the advice which you give so freely to others." Again, a dreamer who has a pain in his head, meets a child who is also suffering from headache, and asks the child to suggest a remedy. Will and attention are wholly lacking in dreams. There is no real adaptation either to internal, to external or to future conditions. There is no resistance, no control, no criticism.

I should like to mention a particular form which the diminution of attention assumes in dreams. Several authors (Egger in France, Schneider in Germany) have pointed out that in dreams only the center of the mental picture is illuminated; the outlying parts are invisible, or rather they are non-existent. The pictures appear without any setting. And it is just this absence of surrounding objects, $i$. e., of environment of thought, which explains the absence of comparison and criticism that is characteristic of dreams.

The study of one's memory of dreams reveals other interesting characteristics of the enfeeblement of attention. In the first place, dream experiences do not become firmly fixed upon the memory. When we awake we fail to remember what we have dreamed, and dreams which do not recur are forgotten as soon as they take place. This is the form of oblivescence which in another connection, I have called continuous amnesia, and it is interesting to note that it is to be found in dreams. But there is an even more peculiar feature; Delage, de Sanctis, and Pilcz have observed that the striking events and the intensive emotions of the day do not reappear in the dreams of the following night. The mother who has just lost a child is surprised to find that she does not dream of her loss although that subject has occupied her mind all day long. These authors furnish different explanations of this fact, which need not be 
discussed here. Let us remark however that the oblivescence of recent experiences is well known under the name of retrogressive amnesia. In this disturbance, as in dreams, events reappear in memory only after they have long since been experienced. By way of summary, we may say that dreams are characterized by a narrowing of the field of consciousness, by continuous and by retrogressive amnesia.

Other phenomena which are equally semi-normal and semipathological, appear in the emotions. When an individual finds himself suddenly placed in a position to which he is not already adapted by previous habituation, when he lacks the time or the strength required to adapt himself to the new conditions, he experiences certain forms of physical and mental perturbation which are of prime importance. In this country where the James theory of the emotions was developed I need not discuss the emotional value of the visceral excitations. The increase of heart-beat and of respiration, and the spasms of the digestive organs, are well-known features of the state of emotion. It is also known that hunger assumes an exaggerated form in emotion, a phenomenon which in all probability gave rise to the custom of feasting at funerals. These internal excitations extend to the muscles of the members, and in many emotions one may observe an indefinite repetition of violent and useless movements, grimaces and convulsive contortions of all sorts. Numerous authors have been pleased to find in these incoördinated movements, a trace of more or less complete acts which are inhibited in their initial stages in the modern subject; that is, to regard them as vestigial products of movements which attained complete execution when our human or animal ancestors were exposed to similar conditions of stimulation. Stanley Hall's and Dewey's investigations of anger give us a great deal of information upon this point. Moreover it frequently happens that the tics, the various forms of tetanus and the impulses to flee or to cry out, remain undeveloped in the presence of emotional states.

But we must not confine ourselves to the peripheral manifestations of emotion. The weak point of the famous theory is to be found in the dictum that: "We are sorry because we 
cry'-an objection which has been urged by many authors (Irons, Gardiner, Soury, Dearborn, Sherrington, Baldwin and others). Side by side with these motor phenomena, which have quite correctly been called extra-motions, there occur intra-motions which constitute retroactive modifications of consciousness; and these psychical resultants are no less important than their physiological concomitants. Emotion is attended by a mental agitation, just as it is attended by a physical agitation. A multitude of ideas surge into consciousness and disturb the equilibrium. Some years ago, attention was called to a phenomenon which has since been referred to as the hypermnesia of the dying. Those who have escaped from imminent danger report that at the moment of impending death they saw before them as in a panorama, the chief events of their lives. This is simply a case of the phenomenon of hyper-ideation which characterizes many of the emotions. Dreams, muttering in somnambulistic states, hallucinations, and even indefinite interrogations are only an exaggerated form of the phenomena observed in the normal individual who talks to himself of an event which has made a violent appeal to his emotions.

Then too the emotions are characterized by feelings which are analogous to those already discussed - feelings of weariness and of powerlessness. The subject's personality undergoes a change; he no longer feels like himself, and even the external world loses its reality in greater or less degree.

Depression is no less a feature of emotion than is agitation. The depression may be visceral; it may manifest itself in a diminution of circulation or of respiration (which in emotion as in sleep, assume the intermittent type of Cheyne Stokes), in impairment of digestion and in gastro-intestinal debility. It may be motor, and evince itself in all the forms of weakness and paralysis which are found to attend certain emotions. A passage from Tolstoi which has been cited by Dumas in his book on ' $L a$ tristesse et la joie,' furnishes an excellent illustration of this feature: "The assassins could easily have escaped from the scene of their crime, but they were so overcome by emotion, so enfeebled in all their limbs that they found themselves incapable of flight. Feeling wearied as though by a long walk, they lay 
down upon the road, and there they remained until they were arrested." The mental depressions are particularly interesting. Popular observation noticed long ago that the individual, when overcome by emotion, is ' not himself,' that he is 'beside himself.' And I have shown on numerous occasions that the characteristics which have been acquired by education and moral development may suffer a complete change under the influence of emotion. People who have learned to speak correctly revert to dialect or resume a foreign accent when they are deeply moved. Their writing becomes confused, clumsy, boyish and full of faults; their whole character becomes coarse and debased. These general depressions are analogous to more definite disorders, and here again the disturbances of memory must be mentioned. Oblivescence of the event which occasioned the emotion, and inability to remember facts which immediately preceded, have frequently been found to accompany intensely emotional experiences in the form of continuous and retrogressive amnesia. But it must not be thought that these phenomena are merely pathological caprices. They are an exaggerated form of a general disturbance of memory which is characteristic of all emotions.

In his celebrated book on Mind and Body, Hack Tuke remarked that emotions frequently render the subject insensible, and he reported having seen subjects become blind and deaf as the result of violent emotion. I too have described many similar observations and they have now become a common-place. These disorders of sensibility and memory are analogous to certain disturbances of perception and attention; and the analogy holds alike whether the object of apprehension be one's self or whether it be the external world. As to will, there can be no doubt that it disappears in the depressive emotions and that the subject, when under intense emotion, is unable to decide what to do; indeed he even loses the power to act upon previous decisions. Hence one may well ask whether the mental commotion is not a more important characteristic of the emotion than is the visceral change. And one seems justified in regarding the consciousness of an emotional state as being something more than a mere counter-effect of peripheral disturbances. 
These intellectual modifications, these losses of memory, these lacks of decision, these doubts, these failures to see reality as it is and to react upon it as one has previously learned to do, together with the feelings of depression which result from the changed mental conditions, constitute, in my opinion, the essential feature of emotion; and the sensations which arise as a 'back-stroke' from the peripheral disturbances is nothing more than a reinforcement, like the added tone in the chord.

It is a remarkable fact that certain emotions are attended by effects which are diametrically opposite to those just described. This second type of emotion may induce calmness, strengthen the visceral functions, arrest the useless mental agitation and replace it by an increased activity of attention and will. This improved condition of attention and will strengthens the tenacity of memory; it gives rise to valid representations of reality and to effective reactions upon one's environment. There are emotions which elevate as well as those which depress, emotions which heal as well as those which destroy. And here again as in fatigue and in repose, in sleep and in the waking state, we find a remarkable illustration of the oscillations of mind.

Let us now leave those phenomena which may be regarded as normal and examine the characteristics of mental diseases. Here we shall find phenomena of exactly the same sort as those which have already been discussed. Pathological psychology owes much to the study of hysteria. That hysteria is characterized by phenomena which are analogous to those which have been established in fatigue, in the sleeps, and in the emotions, is clearly evident from the different theories of hysteria which have been advocated. Certain investigators have insisted that hysteria is a purely emotional disturbance (the old theory of Briquet). Others have held that hysteria is a sleep-disease - a neurotic disturbance which is due to an excess of sleep (Sollier). Others again, find an analogy between hysteria and fatigue, and make the former the effect of an excessive degree of the latter (as Féré did in I885). As for myself $\mathrm{I}$ am an out-and-out eclectic; I believe that hysteria is a disorder of emotion, of sleep and of fatigue, because all of them are at bottom exactly the 
same thing. In hysteria one may observe the same intensely exaggerated agitations as are to be found in convulsions, crises, spasms, hallucinations, and in all other cases in which ideas develop automatically as a result of suggestion. One may observe the same feelings of weariness, of powerlessness, and of automatism. "I can see my arms and my legs moving, but it does not seem to be myself. I am a marionette and somebody is pulling the string." One may observe especially the same depressions and the same inefficiency of the higher cerebral functions. Permit me to recall my investigations upon aboulia, aprosexia, and amnesia in hystericals. If an act is even moderately novel, if a situation presents a problem to be solved, the hysterical remains inert and powerless. It is a remarkable fact that the disturbances of mental synthesis which occur in hysteria, bear a close resemblance to the oscillations of mind which have already been described. For example, suggestion which plays so important a rôle in this disease, can only be explained from the absence of antagonistic ideas which might counteract the idea suggested. This fact shows that the idea remains isolated in the mind of the hysterical, that it develops in the midst of a void, that the picture is not inclosed in a frame. And this is exactly what has been found to be characteristic of dreams. The anæsthesias, and frequently the paralyses, of the hysterical, alike consist of a reduction or narrowing of consciousness which is no longer able to make a simultaneous fusion of all the sensations and all the images which come in from without. This is well explained from the remarkable facts which relate to the transference, or better, the equivalence of phenomena in hystericals. One symptom gives place to another, one paralysis is cured and another supervenes, as though the mind were incapable of constituting a single system, and could resume control of one side of the body only at the expense of losing control of the other side. The narrowing of the field of consciousness in hysteria is of the very same sort as we found to occur in sleep and in fatigue.

In hysteria we again find interesting disturbances of memory - continuous and retrogressive amnesia - which are identical with those that occur in dreams and in emotion. It is a familiar 
fact that at the end of an emotion we find that we have forgotten the preceding events, and we are incapable of acquiring the memory of new events. But hysteria is nothing more than this; and that is the reason why an endless discussion has arisen as to whether the hysterical is not merely an individual who has been overcome by emotion, and as to whether traumatic neurosis is not simply hysteria. The narrowing of the field of consciousness seems to me to be the characteristic form which the mental depression assumes in hysteria.

Let us now consider another disease which I have studied these many years, and which I have discussed in my most recent volumes. Let us take a glance at the innumerable disorders which have been designated obsessions, impulsions, insanity of doubt and of touch, tics, phobias, etc. No matter how various their symptoms may appear, it is possible to find certain fundamental characteristics which are common to all of these diseases. Motor, visceral or mental agitation manifests itself in unmistakable form in all of these crises of motor agitation, these contortions and tics of all sorts, and in the anguish which constitutes the essence of all the phobias. Everybody knows the peculiar mental agitation of those abnormal individuals who busy themselves incessantly with some insoluble problem, who spend whole days in an endeavor to remember what they did at a certain hour on a certain day ten years ago; who exhaust themselves in attempts to understand why trees are green, or why people have noses; who try to count all the objects they see, or to atone for every act by an appropriate exorcism.

All of these agitations seem to have their source in certain feelings which are extremely varied and interesting. I shall mention only the most familiar forms. In connection with all his acts the subject experiences feelings of difficulty, of inutility, of incapacity, of indecision, of uneasiness, of automatism, of domination, of discontent, of humility, of shame, of intimidation, and of revolt. In connection with his intellectual operations he has feelings of difficulty, of insufficiency, of instability, of imperfect perception, of gloom, of strangeness, of jamais-vu, of mal-orientation, of isolation, of mal-recognition, of $d \dot{e} j \dot{j}-v u$, of presentment, of unreality, of dreaming, of the lapse of time, of 
lack of intelligence, of obscurity, of doubt. In connection with his emotions there occur feelings of indifference, of weariness, of anxiety, of ambition, of need of excitement. In connection with his personality one may note feelings of self-estrangement, of double-personality, of depersonalization, of death, etc.

These feelings are far from being fictitious; they are based upon a real depression of the physiological functions. It is possible to establish real disorders of will which are manifested in indolence, irresolution, slowness, enfeebled effort, fatigue, failure of achievement, absence of resistance, misoneism, social aboulia with insurmountable timidity, professional aboulias and inertias of all sorts. One may establish disorders of intelligence which are manifested in amnesias, doubts, arrests of instruction, unintelligibility of perceptions, inattention, reveries, and veritable eclipses of mind. In connection with the emotions one may note indifference, melancholy, need of loving and of being loved, fear of isolation, and a return to childhood.

It is quite probable that depression phenomena similar to those just discussed, and that feelings of imperfection similar to those just summarized, are fundamental to many of the deliriums. In the delirium of persecution there are many phenomena of this sort, along with disturbances which are vaguely designated disorders of the general sensibility, and which characterize the first period of inquietude.

If these symptoms of depression - the motor retardation, the difficulty of apprehension and of association - become aggravated, one finds various forms of melancholia, whose interpretation constitutes an important problem of pathological psychology. Indeed, it is the chief problem as Kraepelin and his pupils have pointed out. Certain of these depressions are definitive and irreparable; they terminate more or less rapidly in one or other of the forms of dementia. Other depressions are transitory and curable. Is it possible to distinguish them, from the outset? That is, at the present time, one of the most important practical problems.

It is a remarkable fact that almost all of the depressions which we have discussed - hysteria, psychæsthenia, as well as melancholia - may under certain circumstances, disappear or 
change into the opposite condition. We may designate this change as an excitation in order to distinguish it from the previous agitation which accompanied the depression. A hysterical subject may find herself changed as the result of a crisis, a somnambulism or a suggestion. "I am no longer the same," she says, "I feel new life. My head seems new." She is impressed by the fact that she perceives things much more distinctly than before. "I seem now to see the present objects for the first time. I saw them before, it is true, but they appeared to be in a distant fog. It is only now that I really recognize them." These feelings extend to other functions; it seems to her that she breathes more freely, that her arms and her legs are stronger but at the same time she has a much more intensive feeling of fatigue. The subject's conduct has undergone a complete change; she sets to work; she resumes her trade without ennui and even with interest. She is capable of making whatever coördinations are necessary, while in her previous condition she remained passive and inert for an indefinite period of time. Her sociability and her natural feelings return to full activity. I have elsewhere described changes of this sort in connection with the influence of hypnotism, and the necessity of direction in hystericals. ${ }^{3}$

It is to be noted that these changes appear in exactly the same form in psychæsthenic subjects, as the result of certain emotions, as the result of acts which they have been made to perform, or simply in consequence of exhortation or advice after their confidence has been won. Their disorders of perception, their doubts as to the reality of things and of themselves, disappear and are replaced by feelings of certainty which delight the subject beyond measure. He comes to know himself again, and he experiences deep feelings of emotion, of joy and sorrow, to which he had formerly been a comparative stranger. This change is accompanied in many cases by feelings of joy and delight which it is very important for us to know if we are to understand the mental states of certain religious ecstatics which science is only now beginning to analyze.

I can only indicate the most striking phenomena which I

${ }^{1}$ Nevroses et idkes fixes, $1898, \mathrm{Ch} . \mathrm{XI}$. 
have observed in connection with the influence of toxines in determining these periods of excitation. Of prime importance for the theory of these diseases is the fact that the fever induced by an intercurrent disease frequently suffices to cause the disappearance of depression and of all disorders depending upon it. I have called attention to certain curious cases in which the development of phthisis has brought about a cure of mental diseases. Women who have been subject to obseșsions or agrophobia for twenty years without interruption, regain their calmness and moral assurance during the last months of their lives, when the progress of tuberculosis induces a slight degree of continuous hectic fever. But what I wish to emphasize here is the simple fact that all the symptoms of depression may disappear and give place to an opposite condition.

This is still more evident in the melancholic states of which we have just been speaking. It is known that melancholia may give place to a state of more or less normal excitation in which many of the preceding phenomena are reversed. This is what the older French alienists (Morel, Baillarger), and more recently Ritti, studied under the name of intermittent insanity, circular insanity, and insanity of dual form. This too is what the German alienists are taking up again under the name of depressive insanity, to which they rightly ascribe a great importance. The physiological and the mental conditions presented by these two contrary forms which alternate in the same individual, were carefully investigated by Dumas in his work on La tristesse et la joie. It would, in my opinion, be most desirable to analyze the states of mental excitation with the same care as has been given to the states of depression. It would be well to discover if the apparent exaltation of mind is real, to determine what pathological phenomena it manifests, and to ascertain whether it can, like depression, become the starting-point of delirium. It is at least certain that depressed subjects believe the ascending oscillation to be possible, that they desire it, and that they make every effort to attain it. Many of the impulsions are due to this fact. Dipsomania is in reality a crisis of depression in which the subject feels the need of being excited by means of a poison whose effects he knows only too well, $i$.e., by alcohol. And there are many impulsions of the same sort. 
How are we to envisage these transformations which are still far from being understood? It will suffice to summarize them in the form of a general hypothesis which may serve at once to resume a great many facts, to provoke discussion, and to instigate investigation. The phenomena which we have passed in review testify to the fact that the various functions of the nervous system are not all of equal difficulty. Certain functions are more facile than others, and require a lesser amount of nervous energy for the production of their mental phenomena. These functions seem to be arranged in a hierarchy of increasing degrees of difficulty; for when a nervous system loses or regains its strength, its functions disappear or reappear in a regular sequence. The functions which are the first to disappear are evidently the most complex, i. e., those which are concerned with the synthesizing of a great number of sensations and images. We must therefore take account, as has been done particularly in England since the work of Hughlings Jackson, of the order of development of cerebral centers and cerebral functions. The functions which are the last to be developed in the race and in the individual are evidently the most complex and difficult ; they will naturally be most readily affected in fatigue, in sleep, in emotion and in diseased conditions of the nervous system. Finally, I believe that these two notions may be united by the introduction of an additional conception. The mental operations which are at once most difficult of accomplishment and most recent in origin, are those whose function it is to bring the individual into relation with the given reality of the moment. They are most complex because reality is in touch with us at so many points, and most recent because the world about us is constantly changing. Evolution is not a thing of the past alone; we are constantly called upon to adapt ourselves to new situations, and to evolve new organs and new functions as our animal ancestors did in developing to our present condition. Now, one can readily see that it is just the adaptation to the present reality, the reaction upon reality, the feeling and enjoyment of reality, which disappears in all depressions, and which, on reappearing in the subsequent excitations, gives rise to feelings of joy and gladness. 
Below these highest functions are to be placed those mental operations which occur when present reality is to a certain extent ignored, and the present reaction consists in an automatic repetition of the past. "I must not pay attention; my work will not proceed satisfactorily if I become absorbed in it." Still lower down, we must place the abstract mental operations; these have to do solely with few and non-complex images, nor are they concerned with new adaptations. It is a mistake to suppose that abstract reasoning, imagining and remembering are the highest mental operations. These are of value only when they are engaged upon the (concrete) present; so soon as they become abstract they cease to be difficult, and prove to be most common-place achievements. A high degree of development of purely representative memory is frequently attained by savages, by children, by the feeble-minded, and by the insane. Still lower down, we would have uncoördinated visceral excitation, such as is present in the emotions, in the uncoördinated motor agitations, in tics and in convulsions.

In short, the mental functions disappear more readily in proportion as their coefficient of reality is higher, and persist longer in proportion as their coefficient of reality is lower. Thus from the point of view of knowledge and of action, or of their correspondence with each other (Spencer), the mental functions constitute a series of decreasing difficulty, according as their relation to reality diminishes. If we consider these conceptions in connection with the philosophical views of Spencer, Höffding, Ribot, and Bergson, they throw light upon many of the observations and experiments of pathological psychology.

They permit us to take our stand upon a first group of facts relating to the lowering of the mental level in various conditions and diseases, and to interpret the changes which attend the various excitations, as a subsequent elevation of the mental level. In short they permit us to regard as mental oscillations, a host of phenomena which fail to find a place within the limits of a system of normal psychology. A psychology which confines itself to the study of normal mankind has a tendency to deal only with immutable and complete conditions. It is to a considerable degree static; it describes man as he ought to be, and 
it does so in a definitive manner. It has a fondness for the functions which seem to be invariable, such as reason, representative memory, or the intellect in general. Such important phenomena as those of fatigue are not even mentioned in the older psychologies. Fatigue had no place in the older text-books because it was not regarded as a function; it was only a disorder. The older psychologists were equally at a loss in their discussion of sleep and dreams; these were regarded as mental curiosities and were relegated to an appendix at the end of the volume. And as to the emotions, they were misunderstood to the extent of being made phenomena either of intellect or of pure sensation. Pathological psychology has rehabilitated all these phenomena, and has pointed out their supreme importance. We cannot afford to ignore fatigue, sleep and emotion, since they are typical of all the mental diseases. If we ignore them we must also ignore hysteria, obsessions, melancholia and mania. And what would be left? In my opinion, it was psycho-pathological investigation which introduced into psychology the disposition to pay more attention to the evolution of mind as manifested in the phenomena of mental augmentation and mental diminution. In a word, psycho-pathology has made psychology more dynamic, and it seems to me, has also deepened it, and brought it closer to reality.

This rapid sketch shows us what has been the direction taken by the chief investigations of pathological psychology. We have summarized the results of numerous investigations which have already been made, and have indicated the trend of those that are to come. What problems are set for us to solve by the notion of an oscillation of the mental level ? What phenomena are characteristic of the depression and of the reellevation (excitation) of the level ? In other words, what precise position in the hierarchy is occupied by each mental function? A rapid association of ideas, and a development of automatism do not always indicate an elevation. There are agitations which coincide with depressions, and which may be regarded as a sort of derivative. How does the derivation come about? How do the phenomena belonging to a lower level replace a vanished phenomenon of a higher level? What are the characteristics 
of excitation, which has been studied much less than depression? What factors determine these two groups of phenomena? How does it come that in different diseases these phenomena appear now in one form, now in the alternate form? What is the mental result of the indefinite prolongation of a state of depression or of excitation? The answers to these questions will doubtless some day help us to solve the difficult problem of the classification of mental diseases. Finally, is it possible to discover therapeutic agents, whether physical or mental, which will act upon the oscillations? Our knowledge upon all of these points is still in a rudimentary stage. But it seems safe to assert that the notion of the elevation of mental levels is beginning to assume a definite form; and that it has opened up to us an important chapter of pathological and of normal psychology. 